Evelise Dias Antunes ${ }^{\mathrm{a}, \mathrm{b}}$

(iD) https://orcid.org/0000-0002-1875-5538

Frida Marina Fischer ${ }^{\mathrm{b}, \mathrm{c}}$

(iD) https://orcid.org/0000-0001-9403-6300

a Instituto Federal do Paraná (IFPR).

Curitiba, PR, Brasil.

b Universidade de São Paulo (USP), Faculdade de Saúde Pública, Programa de Pós-Graduação em Saúde Pública. São Paulo, SP, Brasil.

' Universidade de São Paulo (USP), Faculdade de Saúde Pública, Departamento de Saúde Ambiental. São Paulo, SP, Brasil.

Contato:

Evelise Dias Antunes

E-mail:

evelise.antunes@ifpr.edu.br

As autoras declaram que o trabalho não foi subvencionado e que não há conflitos de interesses.

As autoras informam que o trabalho não foi apresentado em evento científico.

Trabalho baseado em resultados de pesquisa de doutorado de Evelise Dias Antunes, em andamento na Faculdade de Saúde Pública da Universidade de São Paulo.

\section{A justiça não pode parar?! Os impactos da COVID-19 na trajetória da política de teletrabalho do Judiciário Federal}

\author{
Can't justice stop?! The COVID-19 impact on the \\ Brazilian Federal Judiciary teleworking policy
}

\section{Resumo:}

Introdução: o teletrabalho tornou-se um recurso necessário diante da crise de emergência em saúde pública causada pelo novo Coronavírus (Sars-CoV-2). Objetivo: analisar a trajetória da regulamentação do teletrabalho no Setor Judiciário Federal e como foi impactada pela pandemia da COVID-19. Métodos: estudo descritivo com base em resoluções que regulamentaram o teletrabalho na Justiça Federal. Resultados: o teletrabalho foi iniciado no Judiciário Federal em 2013, quando o Tribunal da $4^{\text {a }}$ Região publicou a primeira resolução a respeito. Em 2016, o Conselho Nacional de Justiça o regulamentou nacionalmente e cada Tribunal emitiu normativas complementares. Diante da pandemia, para não paralisar suas atividades devido ao isolamento e ao distanciamento social, oJudiciário Federal rapidamente estabeleceu o teletrabalho integral e compulsório a todos os magistrados, servidores e estagiários, porém com a adoção de diferentes metas e ações pelos tribunais. Aspectos ambientais, individuais e familiares, da organização e da natureza do trabalho devem ser observados na implementação do teletrabalho. Conclusão: os resultados sugerem que os desafios da realização do teletrabalho durante a crise devem contribuir para análise e aperfeiçoamento das normas, metas e políticas públicas vigentes em teletrabalho no Judiciário e nos demais setores, assim como para o entendimento e prevenção dos seus impactos à saúde dos trabalhadores e trabalhadoras.

Palavras-chave: teletrabalho; justiça federal; COVID-19; políticas públicas; saúde do trabalhador.

\begin{abstract}
:
Introduction: working remotely has become a necessary resource in face of the public health emergency crisis caused by the new Coronavirus (Sars-CoV-2). Objective: to analyze the trajectory of remote working regulation in the Brazilian Federal Judiciary and how the COVID-19 pandemic outbreak affected that process. Methods: descriptive study based on the federal judiciary teleworking regulations. Results: the federal judicial system started to adopt teleworking in 2013, when the Forth Region Court published the first resolution on this topic. In 2016, the National Council of Justice regulated it nationally and each Court issued additional regulations. Due to the pandemic and aiming at keeping its activities during lockdown and social distancing measures, the Federal Judiciary quickly established full and compulsory remote working to all magistrates, civil workers and trainees. However, each court adopted different goals and took distinct actions. Individual and family aspects, as well as work environment, organization and nature were considered for the teleworking implementation. Conclusion: the results suggest that the challenges of remote working during the pandemic crisis should contribute to the analysis and improvement of current regulations, goals and public policies, whether in the Judiciary or in all other sectors, as well as to understand and prevent their impacts on workers' health.
\end{abstract}

Keywords: teleworking; federal court; COVID-19; public policies; occupational health.
Recebido: 10/08/2020

Revisado: 06/10/2020

Aprovado: $14 / 10 / 2020$ 


\section{Introdução}

Novos desafios ao mundo do trabalho não eximem as instituições públicas brasileiras. A pandemia da COVID-19 impactou o mundo, a vida, o meio ambiente, a economia, tecnologia, as instituições e as relações em uma velocidade sem precedentes. Em 30 de janeiro de 2020, a Organização Mundial da Saúde (OMS) declarou que o surto da doença causada pelo novo Coronavírus constituía uma Emergência de Saúde Pública de Importância Internacional - foi a sexta vez na história que isso ocorreu $^{1}$. Em 11 de março de 2020, a COVID-19 foi caracterizada pela OMS como uma pandemia.

Em 3 de fevereiro de 2020, o Ministério da Saúde do Brasil declarou Emergência em Saúde Pública de importância nacional em decorrência da infecção humana pelo novo Coronavírus ${ }^{2}$. Sendo que 45 dias depois foi anunciado o estado de transmissão comunitária em todo o território nacional.

No mundo, foram confirmados 45.963 .075 casos de COVID-19 e 1.192.830 mortes. Já o Brasil confirmou 5.516.658 casos e 159.477 mortes até o dia 1 de novembro de $2020^{1}$. As medidas preventivas recomendadas pela OMS são o isolamento e distanciamento social diante de uma doença desconhecida, causada por um vírus que possui longa permanência em superfícies e sem tratamentos conhecidos ${ }^{1 .}$

A pandemia como um fenômeno social trouxe mudanças à sociedade, fomentando diversas perguntas, como: diante de um momento nunca vivido, como repensar o trabalho? Quais indicadores são relevantes para a definição de políticas públicas, estratégias e ações de enfrentamento relacionadas ao trabalho? O setor Judiciário pode parar? Por quanto tempo? Mesmo diante dessas e de outras perguntas, não houve tempo o suficiente para reflexão e muitas ações tiveram que ser desenvolvidas rapidamente. As experiências de outros países mostravam que as decisões que usualmente levariam anos sendo deliberadas passaram a ser tomadas em dias ou horas.

As medidas de distanciamento social impostas aos cidadãos estimularam a extensão do teletrabalho na sociedade. A literatura não registrava casos de implementação de teletrabalho como resultado de uma crise de saúde. Uma situação sem precedentes se instaurou, conduzindo a maioria das organizações (públicas e privadas) a pedirem aos seus trabalhadores que trabalhassem remotamente, a partir de casa. Se o risco da COVID-19 não existisse, não haveria uma implementação de práticas de teletrabalho de forma ágil e massiva como a ocorrida.
O Judiciário Federal decidiu em 19 de março pelo teletrabalho compulsório ${ }^{3}$, ou seja, um dia antes do Ministério da Saúde (MS) declarar estado de transmissão comunitária. Recomendações de isolamento e distanciamento social faziam parte da primeira portaria publicada pelo MS e o teletrabalho tornou-se uma resposta rápida à necessidade de implementar uma solução coordenada, porém não isenta de desafios.

O objetivo deste estudo é analisar a trajetória da regulamentação da política de teletrabalho no setor Judiciário Federal Brasileiro e como ela foi impactada pela pandemia da COVID-19. Também visa subsidiar a discussão e aprimoramento das políticas públicas de teletrabalho no Brasil, especialmente nas organizações públicas, uma vez que os marcos legais têm um papel estruturante na implementação de medidas.

\section{Métodos}

Este estudo é de natureza descritiva ${ }^{4}$, com base documental e normativa, tendo como objetivo a compreensão, explanação e especificação de um fenômeno. Empregou-se o método comparativo ${ }^{4}$ pela investigação de instituições, fenômenos e fatos, com vistas a ressaltar as diferenças e similaridades entre eles.

Como procedimento metodológico, é utilizada a análise qualitativa de conteúdo ${ }^{5}$ compreendendo que, ao analisarmos e interpretarmos os resultados, contrastaremos tanto a diferença quanto a homogeneidade em busca da construção de uma matriz de análise. Constituem-se como fontes documentais as Resoluções que regulamentaram o teletrabalho na Justiça Federal de 2013 até junho de 2020.

Também nos valemos da análise de políticas, que consiste em um processo (policy process) que se distingue nas fases de agenda, formulação, implementação e avaliação. Esse processo abrange não só a interação entre diversos elementos, como também problemas, soluções, atores e interesses, dentre outros ${ }^{6}$.

A partir da observação do ciclo de análise de políticas ${ }^{6}$, esta pesquisa tem como recorte a análise da fase de formulação. Essa etapa consiste no estabelecimento da política, ou seja, nesse caso são os documentos promulgados (resoluções). Nessas resoluções, estão definidos os objetivos, metas, aspectos referentes a implementação com vistas a resolver a demanda da realidade - a agenda da política.

A pesquisa foi aprovada junto ao Comitê de Ética e Pesquisa da Faculdade de Saúde Pública da USP sob número 15180319.9.0000.5421. 


\section{Resultados e discussão}

\section{Precedências do teletrabalho}

O teletrabalho é um assunto discutido mundialmente, inspirando pesquisas sobre transporte, planejamento urbano, ética, direito, estudos organizacionais e trabalho moderno ${ }^{7-16}$. O precursor dos estudos sobre essa modalidade foi o americano Jack Nilles ${ }^{11}$, que tinha como foco o impacto potencial da utilização de telecomunicações e tecnologia de computadores como alternativa ao transporte urbano, criando estações de trabalho em centros próximos às casas ou nelas próprias, evitando o deslocamento para o trabalho.

As estatísticas apresentadas no relatório da Organização Internacional do Trabalho ${ }^{10}$ (OIT) mostram que o teletrabalho está em ascendência, em ritmo acelerado, desde o início do século $21 \mathrm{em}$ toda a Europa. Alguns exemplos representativos são a França, com aumento de 7\% (em 2007) para 12,4\% (em 2012), e a Suécia, onde teletrabalhadores aumentaram de 36\% em 2003 para 51\% em $2014^{9}$.

Diferentes denominações são encontradas nas línguas portuguesa e inglesa para a modalidade. Em português temos teletrabalho, trabalho em domicílio, à distância ou remoto, e na língua inglesa encontramos os termos home-working, nos Estados Unidos, e telecommuting, na Europa. Há ainda outras variações, incluindo telework, work-at-distance, off-site work e remote work. A ideia principal é a mesma, de que as atividades de trabalho sejam realizadas fora das instalações da empresa.

Entretanto, distingue-se aqueles que trabalham principalmente de casa de trabalhadores móveis (que atuam em diferentes locais), assim como a frequência e o uso feito da tecnologia (Quadro 1). Considera-se que esses aspectos, de acordo com a intensidade, podem ter diferentes consequências para as condições de trabalho ${ }^{10}$.

No Brasil, a Consolidação das Leis do Trabalho (CLT) (Art. 75-B, Lei $\mathrm{n}^{\circ}$ 13.467/2017) ${ }^{17}$ definiu teletrabalho como "a prestação de serviços preponderantemente fora das dependências do empregador, com a utilização de tecnologias de informação e de comunicação que, por sua natureza, não se constituam como trabalho externo".

A implementação do teletrabalho na governança pública brasileira iniciou-se no Serviço Federal de Processamento de Dados (SERPRO) com um projeto piloto em 2006. Seguiram-se o Tribunal de Contas da União (TCU) em 2009, Receita Federal em 2010 e Advocacia Geral da União em 2011. No Poder Judiciário, foi regulamentado pelo Conselho Nacional de Justiça (CNJ), em 2016, por meio da Resolução n ${ }^{0} 227 / 2016^{18}$, chegando ao Supremo Tribunal Federal em $2018^{19}$.

O $\mathrm{CNJ}^{18}$ definiu teletrabalho como "modalidade de trabalho realizada de forma remota, com a utilização de recursos tecnológicos". Já o Tribunal Regional de Justiça da $4^{\text {a }}$ Região ${ }^{20}$ (TRF4) o definiu como "atividade laboral executada, em parte ou em sua totalidade, em local diverso daquele estabelecido pela administração para a realização do trabalho presencial atribuído à unidade de lotação, mediante a utilização de tecnologias de informação e de comunicação". Foi subdividido em duas categorias, sendo teletrabalho em domicílio, "aquele executado na residência do servidor" e teletrabalho distribuído ${ }^{20}$.

Quadro 1 Categorias de teletrabalho de acordo com o uso de tecnologia de informação e de comunicação e local de trabalho

\begin{tabular}{|l|l|l|l|}
\hline \multicolumn{1}{|c|}{ Modalidade } & \multicolumn{1}{|c|}{ Definição } & \multicolumn{1}{c|}{ Uso da tecnologia } & \multicolumn{1}{c|}{ Local de trabalho } \\
\hline $\begin{array}{l}\text { Teletrabalho } \\
\text { regularmente } \\
\text { em casa }\end{array}$ & $\begin{array}{l}\text { Trabalhadores que trabalham regularmente } \\
\text { a partir de casa utilizando tecnologias de } \\
\text { informação e comunicação (TIC). }\end{array}$ & $\begin{array}{l}\text { Sempre ou quase o } \\
\text { tempo todo. }\end{array}$ & $\begin{array}{l}\text { De casa, várias vezes ao mês. } \\
\text { Em outros locais, (exceto as } \\
\text { instalações do empregador) com } \\
\text { menor frequência. }\end{array}$ \\
\hline Alta mobilidade & $\begin{array}{l}\text { Trabalhadores que trabalham regularmente } \\
\text { em vários locais, com elevado nível de } \\
\text { mobilidade, e utilizam TIC. }\end{array}$ & $\begin{array}{l}\text { Sempre ou quase o } \\
\text { tempo todo. }\end{array}$ & $\begin{array}{l}\text { Várias vezes por semana, em pelo } \\
\text { menos dois locais que não sejam } \\
\text { as instalações do empregador, } \\
\text { ou diariamente em pelo menos } \\
\text { um outro local. }\end{array}$ \\
\hline Ocasional & $\begin{array}{l}\text { Trabalhadores que trabalham em um } \\
\text { ou mais locais fora das instalações do } \\
\text { empregador apenas ocasionalmente e com } \\
\text { grau de mobilidade muito inferior ao do } \\
\text { grupo de alta mobilidade. }\end{array}$ & $\begin{array}{l}\text { Sempre ou quase o } \\
\text { tempo todo. }\end{array}$ & $\begin{array}{l}\text { Menor frequência e/ou menos } \\
\text { locais do que o trabalhador de alta } \\
\text { mobilidade. }\end{array}$ \\
\hline
\end{tabular}

Fonte: Eurofound e Organização Internacional do Trabalho ${ }^{10}$ (tradução nossa). 
Diversas perspectivas que influenciam no teletrabalho são discutidas na literatura. Belzunegui-Eraso e Erro-Garcés ${ }^{21}$ ampliam a abordagem proposta por Baruch e Nicholson ${ }^{7}$ e consideram cinco fatores que podem favorecer o teletrabalho. Primeiro, as dimensões individuais, como alta escolaridade, idade, sexo, raça, atitudes pessoais e necessidades. No Brasil, foi identificado na Pesquisa Nacional de Amostra por Domicílios (PNAD) ${ }^{22}$, durante a COVID-19, maior uso de teletrabalho por homens brancos e com ensino superior. O segundo aspecto, também de natureza individual, são a casa e a família, considerando-se a presença de crianças, as relações familiares, assim como a infraestrutura (espaço físico) e a posse e uso de computadores ${ }^{7,21}$.

O terceiro fator a ser levado em conta é a natureza do trabalho e o uso da tecnologia ${ }^{7,21}$. Trabalhadores do "conhecimento", caracterizados por alta qualificação, grande quantidade de trabalho, necessidade de concentração, algum grau de autonomia e uso da tecnologia, são os principais teletrabalhadores ${ }^{10}$. Não obstante, o quarto aspecto é a estratégia e cultura organizacional $^{7,21}$. Essas impactam na organização do tempo, flexibilidade de local, performance, confidencialidade da informação, entre outros aspectos ${ }^{10}$.

O quinto fator elencado abrange meio ambiente, segurança e aspectos legais ${ }^{21}$. Dos impactos ambientais relacionados à urbanização e ao trânsito emergiu a necessidade do teletrabalho ${ }^{11,21}$. Quanto à segurança, há poucos estudos que analisam a relação entre o teletrabalho e problemas que emanam de desastres naturais ou problemas sanitários ${ }^{21}$. No que tange aos aspectos legais, há necessidade de regulamentos específicos sobre o assunto ${ }^{10,21}$.

\section{Teletrabalho no Judiciário Federal até o início da pandemia de COVID-19}

No ano de 2009, a Justiça iniciou a implantação do processo eletrônico judicial e administrativo ${ }^{23}$. Essa política ainda está em implementação em alguns tribunais, sendo que apenas $16,2 \%$ do total de 28,1 milhões de processos que ingressaram em 2018 o fizeram de forma física ${ }^{24}$. Isso possibilitou a realização do trabalho remoto com uso de tecnologias de informação e comunicação, entre outros fatores considerados, e levou à decisão do Poder Judiciário Federal pela implementação do teletrabalho na Justiça Federal ${ }^{25}$.

Os resultados revelam que o teletrabalho na Justiça Federal foi regulamentado paulatinamente nos cinco Tribunais Regionais Brasileiros, sendo o pioneiro nessa implementação o TRF4, em $2013^{26}$. Essa prática motivou a agenda pela formulação de uma Política Nacional pelo Conselho Nacional de Justiça. Até o primeiro semestre de 2020 , foram encontradas 13 resoluções publicadas a respeito, sendo a primeira de 2013.

Considerando essa e outras experiências bem-sucedidas, em 2015, a Comissão Permanente de Eficiência Operacional e Gestão de Pessoas do $\mathrm{CNJ}$ submeteu à consulta pública uma minuta de Resolução que foi consolidada em 2016, resultando na regulamentação do teletrabalho no âmbito do Poder Judiciário - a Resolução n ${ }^{\circ} 227 / 2016^{18}$, conforme mencionado anteriormente.

A força de trabalho da Justiça Federal é composta por mais de 46 mil pessoas, sendo 1.917 magistrados, 28.410 servidores e 15.682 auxiliares (conciliadores, estagiários, Juízes leigos, terceirizados, trabalhadores de serventias privatizadas, voluntários) ${ }^{24}$. Porém, o teletrabalho não está acessível a todos.

A Resolução ${ }^{0}$ 227/2016 ${ }^{18}$ veda a participação no teletrabalho àqueles que: estejam em estágio probatório, que tenham subordinados, ocupem cargo de direção ou chefia, apresentem contraindicações por motivo de saúde constatadas em perícia médica, tenham sofrido penalidade disciplinar nos dois anos anteriores à indicação (Art. 5, I, Res. 227/2016 CNJ). Também define prioridade aos servidores com deficiência, que tenham filhos, cônjuge ou dependentes com deficiência e gestantes e lactantes. Podemos inferir que essas prioridades atendem à maior necessidade de flexibilização do tempo, diminuindo a quantidade de afastamentos do trabalho. Ainda, prioriza atender aqueles que demonstrem comprometimento e habilidades de autogerenciamento do tempo e de organização, que estejam gozando de licença para acompanhamento de cônjuge, sendo que nesse caso, o teletrabalho apresenta-se como uma solução para preservar um servidor que não tenha substituto diante de um cenário de sobrecarga de trabalho (Art. 5, II, Res. 227/2016 CNJ) ${ }^{18}$.

A realização do teletrabalho é facultativa, a critério dos órgãos do Poder Judiciário e dos gestores das unidades. A fim de adequar, especificar e regulamentar a matéria às suas necessidades, os Tribunais Federais editaram atos normativos complementares em diferentes momentos, como ilustra a linha do tempo das regulamentações do teletrabalho na Justiça Federal (Figura 1).

As diferenças entre os Tribunais Federais, ponderando a extensão continental do país, não são possíveis de serem contempladas nesta discussão. Destacamos que a principal delas é a distribuição populacional por unidade judiciária, que, consequentemente, tem distintos portes e realidades ${ }^{24}$. 


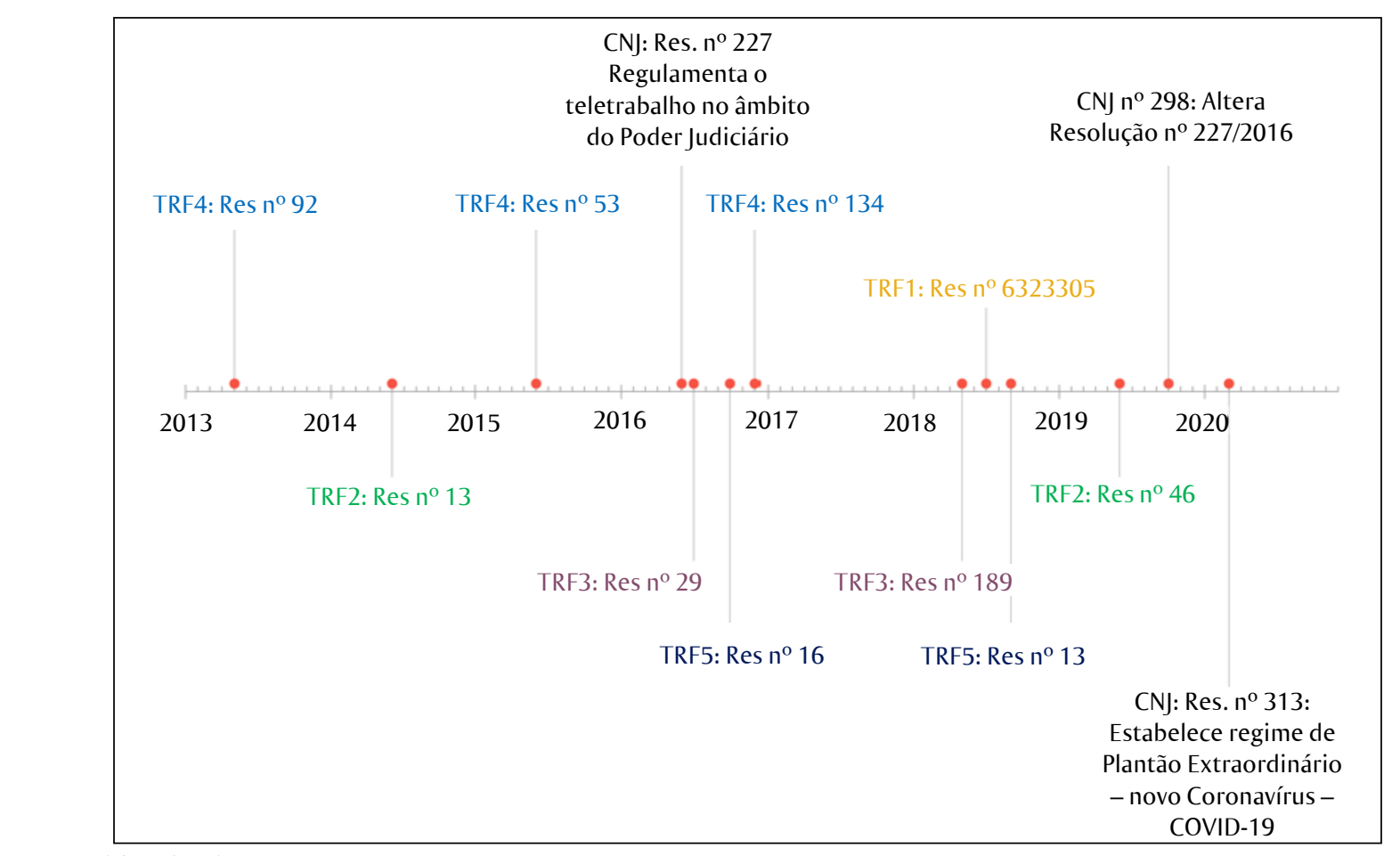

Fonte: elaborada pelas autoras.

Figura 1 Resoluções (13) sobre teletrabalho nos Tribunais de Justiça Federal e CNJ, no período de 2013 a 2020, até o início da pandemia de COVID-19

Na análise das resoluções sobre teletrabalho vigentes nos cinco tribunais, verificamos similaridades nos conteúdos, porém, em diferentes ordens e forma de apresentação, contemplando os itens definidos na Resolução do $\mathrm{CNJ}^{18}$. Todas incluem uma ementa e disposições gerais que contemplam a mesma definição para teletrabalho. Incluem também condições para a realização do teletrabalho. Há extensos itens de direitos e deveres dos servidores, seguidos de deveres dos gestores condensados. Não obstante, contemplam a necessidade de acompanhamento e capacitação, critérios para o cancelamento e disposições finais. Adaptamos as categorias utilizadas pela Organização Internacional do Trabalho (ILO, sigla em inglês para International Labour Organization) ${ }^{27}$ para desenvolver a análise comparativa das resoluções apresentada na Quadro 2.

Em continuidade à análise das resoluções, contrastes significativos foram encontrados no que tange ao estabelecimento das metas e, em um tribunal, à limitação da quantidade de servidores em teletrabalho por unidade (Quadro 3).

A Justiça Federal registrou 70\% de taxa média de congestionamento de processos (indicador percentual de casos que permaneceram pendentes em relação aos que tramitaram no ano), sendo a carga de trabalho de 8.370 processos por magistrado e 693 por servidor da área jurídica no ano de 2018. A taxa de congestionamento é maior na Justiça Federal de $1^{\circ}$ Grau, registrada em $85,6 \%{ }^{24}$.

O aumento da produtividade é um dos benefícios do teletrabalho, segundo apontado na literatura ${ }^{10,12-14,28}$. Corroborando esse entendimento, o primeiro objetivo descrito na resolução do teletrabalho é aumentar a produtividade e a qualidade de trabalho dos servidores. Porém, esse entendimento não é tido como uma consequência do teletrabalho, mas uma exigência para tal. Conforme o artigo $6^{\circ}$, a partir da estipulação de metas de desempenho superiores, é previsto que:

Art. $6^{\circ}$ A estipulação de metas de desempenho (diárias, semanais e/ou mensais) no âmbito da unidade, alinhadas ao Plano Estratégico da instituição, e a elaboração de plano de trabalho individualizado para cada servidor são requisitos para início do teletrabalho.

$\S 1^{\circ}$ Os gestores das unidades estabelecerão as metas a serem alcançadas, sempre que possível em consenso com os servidores, comunicando previamente à Presidência do órgão ou a outra autoridade por esta definida.

$\S 2^{\circ}$ A meta de desempenho estipulada aos servidores em regime de teletrabalho será superior à dos servidores que executam mesma atividade nas dependências do órgão, sem comprometer a proporcionalidade e a razoabilidade, e sem embaraçar o direito ao tempo livre ${ }^{29}$. (grifo nosso) 
Quadro 2 Análise comparativa das resoluções de teletrabalho no Judiciário Federal

\begin{tabular}{|c|c|c|c|c|c|c|}
\hline Áreas-chave das resoluções do teletrabalho/CNJ e Tribunais & CNJ & TRF1 & TRF2 & TRF3 & TRF4 & TRF5 \\
\hline Fornece uma ou mais definições legais (teletrabalho, teletrabalhador) & $x$ & $x$ & $x$ & $\mathrm{X}$ & $\mathrm{X}$ & $X$ \\
\hline $\begin{array}{l}\text { Fornece referência às condições e regras (direitos, aplicabilidade, } \\
\text { duração ou prazo máximo, retorno ao local de trabalho, acesso ao } \\
\text { local de trabalho etc.) }\end{array}$ & $\mathrm{x}$ & $\mathrm{x}$ & $\mathrm{X}$ & $\mathrm{X}$ & $\mathrm{x}$ & $X$ \\
\hline Esboça as condições de proteção de dados & $x$ & $x$ & $x$ & $x$ & $x$ & $x$ \\
\hline Esboça questões de privacidade & & $x$ & & & $x$ & $X$ \\
\hline \multicolumn{7}{|l|}{$\begin{array}{l}\text { Fornece referência à segurança e saúde organizacional } \\
\text { (equipamentos, estresse e saúde mental etc.) }\end{array}$} \\
\hline $\begin{array}{l}\text { Inclui disposições específicas relativas às responsabilidades do servidor } \\
\text { de dispor de espaço físico, mobiliários e equipamentos próprios e } \\
\text { adequados para o teletrabalho e de manutenção de tal equipamento }\end{array}$ & $x$ & $x$ & $x$ & $X$ & $X$ & $X$ \\
\hline \multicolumn{7}{|l|}{$\begin{array}{l}\text { Inclui informações sobre compensação de custos caso o trabalhador tenha } \\
\text { que dispor dos equipamentos* }\end{array}$} \\
\hline $\begin{array}{l}\text { Requer um acordo por escrito entre gestor e servidor como } \\
\text { uma condição para participação no teletrabalho }\end{array}$ & $X$ & $X$ & $x$ & $X$ & $x$ & $X$ \\
\hline \multicolumn{7}{|l|}{$\begin{array}{l}\text { Requer um acordo de negociação coletiva aplicável, } \\
\text { como uma condição para participação no teletrabalho* }\end{array}$} \\
\hline \multicolumn{7}{|l|}{$\begin{array}{l}\text { Requer tanto aos gestores quanto aos trabalhadores } \\
\text { uma capacitação completa em teletrabalho* }\end{array}$} \\
\hline $\begin{array}{l}\text { Fornece informações sobre a organização do trabalho (tempo de } \\
\text { trabalho e horas extras, frequência do teletrabalho, local de trabalho, } \\
\text { carga de trabalho, medição e avaliação de desempenho, metas, relatórios, } \\
\text { monitoramento etc.) }\end{array}$ & $X$ & $X$ & $X$ & $X$ & $X$ & $X$ \\
\hline \multicolumn{7}{|l|}{$\begin{array}{l}\text { Sua aplicação requer uma forma de consulta com os parceiros sociais; } \\
\text { isso inclui uma referência particular relativa à representação coletiva de } \\
\text { teletrabalhadores* }\end{array}$} \\
\hline Requer instituir uma Comissão de Gestão de Teletrabalho & $x$ & $x$ & $x$ & $x$ & $x$ & $X$ \\
\hline $\begin{array}{l}\text { Inclui referência à flexibilidade ou ao direito de desconexão } \\
\text { (não embaraçar o direito ao tempo livre) }\end{array}$ & $X$ & $X$ & & $X$ & $x$ & $X$ \\
\hline Inclui referência à natureza do teletrabalho (voluntário) & $x$ & $x$ & $x$ & $x$ & $x$ & $X$ \\
\hline $\begin{array}{l}\text { Fornece informações sobre como o teletrabalho deve ser } \\
\text { implementado (procedimentos para execução) }\end{array}$ & $X$ & $x$ & $X$ & $X$ & $X$ & $X$ \\
\hline \multicolumn{7}{|l|}{$\begin{array}{l}\text { Fornece informações sobre formalidades, como procedimentos } \\
\text { de comunicação de acidentes* }\end{array}$} \\
\hline $\begin{array}{l}\text { Prevê mecanismos de acompanhamento e capacitação do } \\
\text { servidores e gestores de teletrabalho }\end{array}$ & $X$ & $X$ & $X$ & $x$ & $x$ & $X$ \\
\hline $\begin{array}{l}\text { Solicita declaração de que cumpre todos os requisitos para } \\
\text { realizar o teletrabalho }\end{array}$ & $x$ & $x$ & $X$ & & $x$ & $X$ \\
\hline $\begin{array}{l}\text { Fornece referência a vistoria no local de trabalho durante todo } \\
\text { período de realização do teletrabalho }\end{array}$ & $X$ & & & & & \\
\hline \multicolumn{7}{|l|}{$\begin{array}{l}\text { Esclarece como se dará a vistoria no local de trabalho durante o } \\
\text { período de realização do teletrabalho* }\end{array}$} \\
\hline $\begin{array}{l}\text { Prevê disponibilização no site Portal da Transparência dos nomes } \\
\text { dos servidores que atuam no regime de teletrabalho }\end{array}$ & $X$ & $X$ & $X$ & $X$ & $X$ & $X$ \\
\hline
\end{tabular}

"Essas categorias não constam das Resoluções analisadas.

Fonte: elaborada pelas autoras. 
Quadro 3 Comparação da análise das metas e da limitação da quantidade de servidores nas Resoluções de Teletrabalho no Judiciário Federal

\begin{tabular}{|l|l|l|}
\hline $\begin{array}{c}\text { Tribunal } \\
\text { (ano da } \\
\text { Resolução) }\end{array}$ & $\begin{array}{c}\text { Determinação de metas de desempenho dos servidores em } \\
\text { regime de teletrabalho comparada à dos servidores que } \\
\text { executam a mesma atividade nas dependencias do órgão }\end{array}$ & $\begin{array}{c}\text { Limitação da quantidade de servidores em } \\
\text { teletrabalho por unidade }\end{array}$ \\
\hline CNJ (2018) & Não define porcentagem, porém, deve ser superior & $\begin{array}{l}\text { Definida por proposta da Comissão de Gestão do } \\
\text { Teletrabalho de cada órgão }\end{array}$ \\
\hline TRF1 (2018) & Não define porcentagem, porém, deve ser superior & $\begin{array}{l}\text { Máximo de 30\%, facultada a majoração para 50\%, a } \\
\text { critério da Presidência do Tribunal }\end{array}$ \\
\hline TRF2 (2019) & $\begin{array}{l}\text { Igual ou superior à dos servidores que executam a mesma } \\
\text { atividade }\end{array}$ & $\begin{array}{l}\text { Limitada a 30\%, facultada a majoração para 50\%, a } \\
\text { critério da Presidência do Tribunal ou Diretorias do } \\
\text { Foro das Seções Judiciárias }\end{array}$ \\
\hline TRF3 (2016) & Até 30\% superior & $\begin{array}{l}\text { 30\% de sua lotação, admitida excepcionalmente a } \\
\text { majoração para 50\%, a critério da Presidência do } \\
\text { Tribunal, da Diretoria do Foro da Seção Judiciária de } \\
\text { São Paulo e da Diretoria do Foro da Seção Judiciária } \\
\text { de Mato Grosso do Sul }\end{array}$ \\
\hline TRF4 (2016) & Até 10\% superior & $\begin{array}{l}\text { Limitada a 30\% de sua lotação efetiva, admitida } \\
\text { excepcionalmente a majoração para 50\%, a critério } \\
\text { da Presidência do Tribunal }\end{array}$ \\
\hline TRF5 (2016) & No mínimo 15\% superior & \begin{tabular}{l} 
Limitada a 20\% de sua lotação efetiva \\
\hline
\end{tabular} \\
\hline
\end{tabular}

Fonte: elaborada pelas autoras.

Face à estipulação de meta de desempenho dos servidores em regime de teletrabalho ser superior à dos servidores que executam a mesma atividade nas dependências do órgão, verificamos uma desigualdade entre os tribunais, com variação de $0 \%$ a $30 \%$, apresentadas na Quadro 3.

Perante as diferentes naturezas de atividade, o estabelecimento de metas se dá de maneiras distintas, seja pelas movimentações, quantidade de processos ou tempo para realização de tarefas. As resoluções versam que os gestores das unidades estabeleçam as metas e os prazos a serem alcançados, buscando sempre que possível consenso com os servidores. Dessa forma, não se pode garantir que a participação dos servidores nessa etapa resulte necessariamente na consonância com seus superiores.

Há um rompimento da tradicional troca da força de trabalho pelo tempo do servidor e o servidor passa a ser remunerado por produtividade, e não mais por horas trabalhadas. Ou seja, a administração do tempo ficará sob a responsabilidade do próprio trabalhador, segundo o que dispõe o artigo $7^{\circ}$.

Art. $7^{\circ} \mathrm{O}$ alcance da meta de desempenho estipulada ao servidor em regime de teletrabalho equivale ao cumprimento da respectiva jornada de trabalho. $\S 1^{\circ}$ Não caberá pagamento de adicional por prestação de serviço extraordinário para o alcance das metas previamente estipuladas ${ }^{18}$. (grifo nosso)
Visto que o tempo de deslocamento do servidor presencial não está incluso na jornada de trabalho, no caso do teletrabalhador que cumpre o mesmo horário, com as mesmas ferramentas e a mesma capacidade, por que as metas de desempenho devem ser superiores? O teletrabalho é visto como um privilégio? Aqueles que são estabelecidos como prioridade, como os servidores com deficiência ou que tenham filhos, alcançam um desempenho maior?

\footnotetext{
Art. $7^{\circ}[\ldots]$

$\S 2^{\circ} \mathrm{Na}$ hipótese de atraso injustificado no cumprimento da meta, o servidor não se beneficiará da equivalência de jornada a que alude o caput deste artigo, cabendo ao órgão ou ao gestor da unidade estabelecer regra para compensação, sem prejuízo do disposto no art. 10, caput e parágrafo único, desta Resolução ${ }^{18}$. (grifo nosso)
}

Ainda nos cabe questionar como estabelecer regra de compensação de trabalho dentro da mesma jornada respeitando-se o tempo de descanso do servidor? Ao compararmos com o caso do home office na iniciativa privada, no artigo $6^{\circ}$ da CLT, há previsão de igualdade de condições entre os que trabalham presencialmente e os que trabalham à distância, ao versar que "não se distingue entre o trabalho realizado no estabelecimento do empregador, o executado no domicílio do empregado e o realizado a distância, 
desde que estejam caracterizados os pressupostos da relação de emprego".

Assim como em outros países, como exemplo Portugal $^{30}$, observamos que, em termos de proteção do trabalhador, iguala-se a produção entre os que se submetem às modalidades de trabalho presencial e à distância (Artigo 169º ${ }^{\circ}$ Lei n. ${ }^{\circ}$ 7/2009).

Ademais, consideramos que o teletrabalho na Justiça Federal não estava disponível para todos que o desejassem. No tocante aos resultados apresentados na Quadro 3, a primeira normativa do CNJ em 2016 limitava a quantidade de servidores em teletrabalho por unidade a $30 \%$ de sua lotação, admitida excepcionalmente a majoração para $50 \%{ }^{18}$. Esse fato justifica o resultado encontrado nos Tribunais. No ano passado, a resolução foi alterada, transferindo tal definição para a Comissão de Gestão do Teletrabalho de cada órgão ${ }^{29}$.

Destaca-se, em todas as resoluções, a viabilidade dos gestores proporcionarem o revezamento entre os servidores, ou seja, teletrabalho parcial. Para tanto, o cálculo da quantidade de servidores é diário. Esse modelo, além de favorecer que um maior número de trabalhadores experimente essa modalidade, pode favorecer o convívio social e laboral, assim como o vínculo organizacional e associativo.

\section{Teletrabalho integral e compulsório: a resposta aos desafios da COVID-19}

Em rápida resposta, considerando a preservação da saúde dos trabalhadores, das trabalhadoras e dos usuários, o Conselho Nacional de Justiça, por meio de seu presidente, estabeleceu no âmbito do Poder Judiciário um regime de Plantão Extraordinário para uniformizar o funcionamento dos serviços judiciários e garantir o acesso à justiça nesse período emergencial pela Resolução no $313 / 2020^{3}$.

Esse regime conferiu aos tribunais a possibilidade de disciplinar o trabalho remoto de magistrados, servidores e colaboradores para realização de expedientes internos, como elaboração de decisões e sentenças, minutas, sessões virtuais e atividades administrativas ${ }^{3}$. É a primeira normativa sobre teletrabalho que inclui tanto os magistrados quanto os demais servidores. Nesse momento de pandemia, os prédios dos Tribunais Regionais são fechados e o teletrabalho torna-se compulsório a todos os trabalhadores.

Verifica-se o cuidado do legislador ao utilizar a denominação "trabalho remoto", na Resolução $n^{\mathrm{o}} 313 / 2020^{2}$, do CNJ, em vez de teletrabalho. Inferimos que essa escolha se deu devido às condições excepcionais da pandemia, assim como às normas estabelecidas para sua execução, que diferem das Regulamentações do Teletrabalho. Porém, neste estudo, optamos por utilizar o termo teletrabalho, uma vez que é definido como modalidade de trabalho realizada de forma remota e que também foi o termo utilizado nas Portarias do TRF $3^{31}, \mathrm{TRF}^{32}$ e TRF5 ${ }^{33}$ no período da pandemia.

Prontamente, o teletrabalho integral e compulsório foi estabelecido em todos os Tribunais Federais de Justiça ${ }^{31-35}$. É digno de nota que os prazos processuais foram suspensos pelo CNJ, de 19 de março até o dia 30 de abril de 2020, junto com a implementação do teletrabalho integral e compulsório e o regime de plantão para situações extraordinárias. Porém, a persistência da situação de Emergência em Saúde Pública levou à necessidade de prorrogação do Plantão Extraordinário ${ }^{36}$ e à retomada dos prazos a partir de 4 de maio, assim como à realização de sessões virtuais (audiências e outros).

Mesmo havendo condições excepcionais causadas pela pandemia, a qual podemos considerar uma situação em que se mescla a vida pessoal e profissional, com famílias inteiras confinadas no mesmo ambiente, e dependente da infraestrutura física e tecnológica para o teletrabalho, o CNJ criou o painel "Produtividade Semanal do Poder Judiciário"37. Esse painel mostra todos os atos judiciais e administrativos, ou seja, sentenças, despachos, decisões, acórdãos e alvarás a partir do dia 16 de março. A atualização dos números é automática. Tribunais divulgam seus recordes de produtividade nas suas páginas da internet, servidores em suas redes sociais, enquanto o CNJ alimenta a página comparando todos os Tribunais.

Cabe destacar que não foram estabelecidas metas de teletrabalho nas Resoluções desse período da pandemia, porém também não fica claro se as metas para os servidores que já estavam em regime de teletrabalho estão mantidas. Não é possível discutir o aumento da produtividade, uma vez que foram suspensas atividades presenciais, como audiências e atendimentos, assim como se houve maior pressão sobre os servidores e aumento da carga e tempo de trabalho.

Por fim, evidenciou-se a ação da disposição de equipamentos e/ou mobiliários (a autorização da movimentação excepcional e temporária para suas casas) nas hipóteses em que o magistrado, o servidor ou o estagiário não dispuserem de estrutura adequada em sua residência para a execução do teletrabalho ${ }^{38}$. Esta ação também foi adotada pelo Poder Executivo $^{39}$. Essa ação contrasta com a Resolução do Teletrabalho ${ }^{18}$, que versa:

Art. $9^{\circ}$ Constituem deveres do servidor em regime de teletrabalho:

[...]

$\S 4^{\circ} \mathrm{O}$ servidor deverá dispor de espaço físico, mobiliários e equipamentos próprios e adequados para 
a prestação do teletrabalho. (Incluído pela Resolução $\mathrm{n}^{\mathrm{o}} 298$, de 22.10.2019)

$\S 5^{\circ} \mathrm{O}$ servidor deverá apresentar declaração de que cumpre todos os requisitos para realizar o teletrabalho. (Incluído pela Resolução ${ }^{\circ}{ }^{\circ} 298$, de 22.10.2019) Art. 13. O servidor é responsável por providenciar e manter estruturas física e tecnológica necessárias e adequadas à realização do teletrabalho.

Parágrafo Único. O tribunal não arcará com nenhum custo para aquisição de bens ou serviços destinados ao servidor em teletrabalho. (Incluído pela Resolução $\mathrm{n}^{\mathrm{o}} 298$, de 22.10.2019).

Compreendemos que há uma situação emergencial e temporária, porém, é necessário se perguntar quem deve ser responsável pelos insumos do trabalho, considerando os benefícios e vantagens para a administração do Judiciário, elencados nas regulamentações do teletrabalho. Também é importante considerar que talvez as medidas implementadas no curto prazo possam se estender a médio ou longo prazo. Afinal, não é possível definir quando o trabalho presencial será retomado nos Tribunais Federais. Inferimos isso dada a publicação da Resolução $\mathrm{n}^{\circ}$ $667^{40}$, do Supremo Tribunal Federal (STF), de 29 de abril de 2020, que determina:

\begin{abstract}
Art. $1^{\circ}$ Fica estabelecido modelo diferenciado de gestão de atividades voltado para a entrega de resultados nos trabalhos realizados nos formatos presencial e à distância, a ser aplicado entre $1^{\circ}$ de junho de 2020 e 31 de janeiro de 2021.

$\S 1^{\circ}$ Os servidores em trabalho remoto na data de publicação desta Resolução, seja com fundamento na Resolução no 621, de 29 de outubro de 2018, ou nas Resoluções nos 663, de 12 de março de 2020 , e 670 , de 23 de março de 2020 , deverão ser mantidos em trabalho remoto se a natureza de suas atividades for compatível e houver condições de saúde física e psicológica para a continuidade ${ }^{40}$. (grifo nosso)
\end{abstract}

Essa resolução ainda suspende a aplicação da Resolução $\mathrm{n}^{\circ}$ 621/2018 ${ }^{19}$ enquanto estiver vigente o modelo diferenciado objeto da Resolução $\mathrm{n}^{\mathrm{O}}$ $677 / 2020^{40}$. Esta inclui a suspensão das metas do teletrabalhador, que são no mínimo 15\% superiores àquelas previstas para os servidores não participantes que executem as mesmas atividades ${ }^{19}$. Assim, o STF estrutura uma importante mudança de rotina, demonstrando que os planos de retomada ao antigo normal foram modificados; fala-se agora do novo "normal".

\section{Dimensões para políticas públicas relacionadas ao "tele"trabalho}

O "tele" não se trata de um outro tipo de trabalho, mas sim de uma outra modalidade, ou seja, da mudança do local do trabalho. O STF incluiu na última resolução ${ }^{40}$ a necessidade de condições de saúde física e psicológica para a continuidade do trabalho remoto. Há uma lacuna na política de teletrabalho no Brasil, que deve estar atenta para o desenvolvimento dessa modalidade com base na saúde e segurança do trabalhador.

São necessárias análises em profundidade da implementação de políticas relacionadas ao teletrabalho, não apenas quantitativas, na forma de produtividade, mas qualitativas. O desenvolvimento de novas iniciativas e a implementação devem basear-se em processos que envolvam o diálogo social e a consulta entre todas as principais partes interessadas. Deve-se observar, de maneira macro e micro, as dimensões propostas por Belzunegui-Eraso e Erro-Garcés ${ }^{21}$ para o desenvolvimento do teletrabalho:

a) Individual: personalidade, situação;

b) Trabalho: natureza; tecnologia;

c) Casa e família;

d) Organização: estratégia; cultura.

e) Meio ambiente; segurança; aspectos legais.

O teletrabalho pode proporcionar benefícios como a redução de custos para as empresas, diminuição da poluição do meio ambiente, aumento da produtividade, maior equilíbrio entre a vida profissional e pessoal e diminuição do tempo e custo com transportes ${ }^{8,12,14,16,41}$. Mas deve-se considerar que o aumento da produtividade pode se dar em razão de os teletrabalhadores tenderem a trabalhar mais horas não remuneradas do que no local de trabalho, portanto, uma parte dessa maior produtividade seria pelo aumento do tempo de trabalho real. Soma-se também a diminuição de pausas ou interrupções por colegas e seus superiores, dispendendo menos tempo em atender ligações e comunicações via e-mail ${ }^{10}$.

Salienta-se como aspecto desfavorável o isolamento profissional, podendo afetar negativamente as interações sociais e de amizade, levando à individualização, ansiedade, diminuição do compartilhamento e do conhecimento, dificuldades para realização do trabalho, telepressão, diminuição da comunicação com a equipe, diminuição do reconhecimento e fee$\operatorname{dback}^{15,16,42}$. A intensificação do trabalho feminino, aumentando a divisão sociossexual do trabalho ${ }^{43}$, também é considerada um aspecto desfavorável.

Para Antunes ${ }^{43}$, o teletrabalho e o home office são como um laboratório de experimentação e serão implantados com maior intensidade após a pandemia. O autor considera que há uma relação desigual, na qual as empresas (capital) têm um ganho maior. Para os trabalhadores, os benefícios são a diminuição dos deslocamentos, flexibilidade de horários e melhora na alimentação. Em contrapartida, haveria 
[...] mais individualização do trabalho; maior distanciamento social; menos relações solidárias e coletivas no espaço de trabalho [...] tendência crescente à eliminação dos direitos [...] fim da separação entre tempo de trabalho e tempo de vida (visto que as nefastas metas ou são preestabelecidas ou se encontram interiorizadas nas subjetividades dos que trabalham) $[\ldots]^{43}$. (p. 28)

A falta de regulamentação é também considerada uma das questões mais críticas na implementação do teletrabalho em nível transnacional, na União Europeia ${ }^{21}$.

Os resultados até aqui apresentados demonstram a complexa organização dessa modalidade e uma lacuna na política pública brasileira que regulamenta o assunto, o que demanda aprofundamento em sua discussão.

Não obstante, é necessário que as futuras políticas públicas relacionadas ao teletrabalho estejam atentas aos riscos para além dos destacados por Antunes ${ }^{43}$, de precarização e perda do controle sobre a carga de trabalho, que levam à sobrecarga, fadiga e estresse, ao contexto compulsório ou desejado, ao uso da tecnologia como causadora de interrupções (tais como dificuldades de acesso ao sistema), ao direito à desconexão (sair do local de trabalho), à solidão, à diminuição da empatia e solidariedade, conflitos familiares, intensificação do trabalho decorrente das metas/aumento de produtividade, ao trabalho invisível não valorizado, ao medo de avaliações negativas do trabalho.

Ao construirmos a trajetória de agenda e formulação da política de teletrabalho no Judiciário, a lente da pandemia nos permite ampliar o olhar e dar visibilidade aos problemas pré-existentes, como o aumento da meta dos trabalhadores em teletrabalho no Judiciário.

Outros esforços combinados entre todos os principais interessados são importantes para assegurar que as políticas e conhecimentos existentes sejam traduzidos em práticas eficazes em todo país. É imprescindível discutir e prevenir os riscos de saúde e segurança no local de trabalho remoto.

\section{Conclusão}

A crise gerada pela emergência em saúde tornou o teletrabalho visível por todo o mundo. Compreendemos que o curto período de implementação da política de teletrabalho no Judiciário Federal permite a discussão da norma com o objetivo de analisar e aperfeiçoar as práticas, como previsto pelo próprio CNJ. Não obstante, a experiência do teletrabalho favoreceu uma rápida resposta do Poder Judiciário diante dos desafios da COVID-19.

A comparação das Resoluções sobre teletrabalho dos Tribunais evidenciou a distância entre as normas no que tange ao estabelecimento de metas. Não sabemos como e quando a pandemia terminará, mas se faz necessário programar o retorno e dispor das questões para o teletrabalho que se manifestaram e se manifestarão durante a crise.

Apesar de estudos demonstrarem o aumento da produtividade em teletrabalho nas áreas de informática e telemarketing, há outros que apresentam os resultados como sendo um paradoxo. Este paradoxo se dá em diversos aspectos, desde a diversidade da natureza das atividades, dos conhecimentos, até a percepção das diferenças na adequação das tarefas no teletrabalho. Não obstante, contribui para o desempenho do trabalhador, para sua compreensão enquanto protagonista para produção e para a sociedade.

Talvez mais trabalhadores queiram aderir ao teletrabalho, talvez não. O que está posto é que os processos no Judiciário não são como uma linha de produção mecanizada, pelo contrário, são atividades de trabalho complexas, que não devem substituir sua qualidade na efetivação de direitos por números. Os resultados sugerem a necessidade avaliar as normas e metas previstas, assim como os possíveis impactos à saúde dos trabalhadores e das trabalhadoras.

\section{Contribuições de autoria}

Antunes ED contribuiu em todas as fases da investigação e da redação do manuscrito: concepção, coleta de dados, análise, redação, revisão do texto e aprovação da versão final, e Fischer FM contribuiu na sua concepção, revisão crítica e na aprovação final da versão a ser publicada. Ambas assumem integral responsabilidade pelo estudo e pelo conteúdo aqui publicado.

\section{Referências}

1. World Health Organization. WHO Coronavirus Disease (COVID-19) Dashboard [Internet]. 2020 [cited 2020 sep 9]. Available from: https:// covid19.who.int/
2. Brasil. Ministério da Saúde. Portaria no 188 , de 3 de fevereiro de 2020. Diário Oficial da União [Internet]. 4 fev 2020 [citado em 22 abr. 2020]; 1:24-A. Disponível em http://www.in.gov.br/ 
web/dou/-/portaria-n-188-de-3-de-fevereirode-2020-241408388

3. Conselho Nacional de Justiça (BR). Resolução $\mathrm{n}^{\circ} 313$, de 19 de março de 2020. Diário da Justiça [Internet]. 19 mar. 2020 [citado em 25 abr. 2020]; 1:71. Disponível em: https://atos.cnj.jus.br/atos/de talhar/3249\#: : :text=Estabelece\%2C\%20no\%20 \%C3\%A2mbito\%20do\%20Poder,\%C3\%A0\%20 justi\%C3\%A7a\%20neste\%20per\%C3\%ADodo\%20 emergencial.

4. Gil AC. Métodos e técnicas de pesquisa social. 6a ed. São Paulo: Atla; 2008.

5. Minayo MC de S (Org.)., Deslandes SF, Gomes R. Pesquisa social: teoria, método e criatividade. 34a ed. Petrópolis: Vozes; 2015.

6. Villanueva LA. La implementación de las Políticas. Antologías de Política Pública 4. 3a ed. México, DF: Editorial Porrua; 2000.

7. Baruch Y. The status of research on teleworking and an agenda for future research. Int J Manag Rev. 2001;3(2):113-29.

8. Ruth S, Chaudhry I. Telework: A Productivity Paradox? IEEE Internet Computing. 2008;12(6):87-90.

9. Kwon M, Jeon SH. Why Permit Telework? Exploring the Determinants of California City Governments' Decisions to Permit Telework. Public Pers Manage. 2017;46:239-62.

10. Eurofound, International Labour Office. Working anytime, anywhere: The effects on the world of work. Luxembourg: Publications Office of the European Union, Geneva: International Labour Office; 2017.

11. Nilles J. Telecommunications and Organizational Decentralization. IEEE Trans Commun. 1975;23(10):1142-47.

12. 12. Pigini C, Staffolani S. Teleworkers in Italy: who are they? Do they make more? Int J Manpow. 2019;40(2):265-85.

13. Filardi F, Mercedes R, De Castro P, Tulio M, Zanini F. Vantagens e desvantagens do teletrabalho na administração pública: análise das experiências do Serpro e da Receita Federal. Cad EBAPE BR. 2020;18:(1):28-46.

14. Westfall RD. Does Telecommuting Really Increase Productivity? Commun ACM. 2004;47:93-6.

15. Orhan MA, Rijsman JB, van Dijk GM. Invisible, therefore isolated: Comparative effects of team virtuality with task virtuality on workplace isolation and work outcomes. Rev Psicol del Trab y las Organ. 2016;32(2):109-22.

16. Montreuil S, Lippel K. Telework and occupational health: a Quebec empirical study and regulatory implications. Saf Sci 2003;41(4):339-58.

17. Brasil. Lei $\mathrm{n}^{0}$ 13.467, de 13 de julho de 2017. Altera a Consolidação das Leis do Trabalho (CLT), aprovada pelo Decreto-Lei $n^{\circ} 5.452$, de $1^{\circ}$ de maio de 1943, e as Leis $\mathrm{n}^{\circ} 6.019$, de 3 de janeiro de 1974, 8.036, de 11 de maio de 1990, e 8.212, de 24 de julho de 1991. Diário Oficial da União [Internet]. 14 jul. 2017 [citado em 25 abr. 2020]. Disponível em: https://www.in.gov.br/web/dou/-/ lei-no-13-467-de-13-de-julho-de-2017-19173618

18. Conselho Nacional de Justiça (BR). Resolução CNJ $\mathrm{n}^{\mathrm{o}} 227$ de 15 de junho de 2016. Regulamenta o teletrabalho no âmbito do Poder Judiciário e dá outras providências. Brasília, DF: CNJ; 2016.

19. Supremo Tribunal Federal (BR). Resolução $\mathrm{n}^{\circ} 621$ de 29 de outubro de 2018. Regulamenta o trabalho remoto no Supremo Tribunal Federal. Brasília, DF; 2018.

20. Tribunal Regional Federal da $4^{\mathrm{a}}$ Região. Resolução $\mathrm{n}^{\mathrm{O}} 134$, de 12 de dezembro de 2016. Regulamenta o teletrabalho no âmbito da Justiça Federal de $1^{\circ}$ e $2^{\circ}$ Graus da $4^{\mathrm{a}}$ Região e dá outras providências. Porto Alegre: TRF4; 2016.

21. Belzunegui-Eraso A, Erro-Garcés A. Teleworking in the context of the Covid-19 crisis. Sustainability. 2020;12(9):1-18.

22. Instituto Brasileiro de Geografia e Estatística. PNADCOVID19 | IBGE [Internet]. 2020 [citado em 9 set 2020]. Disponível em: https://covid19.ibge.gov.br/ pnad-covid/

23. Conselho Nacional de Justiça (BR). Resolução $\mathrm{n}^{\circ}$ 185, de 18 de dezembro de 2013. Institui o Sistema Processo Judicial Eletrônico - PJe como sistema de processamento de informações e prática de atos processuais e estabelece os parâmetros para sua implementação e funcionamento. Brasília, DF: CNJ; 2013.

24. Conselho Nacional de Justiça (BR). Justiça em Números 2019. Brasília, DF: CNJ; 2019 [citado em 24 abr. 2020]. Disponível em: https://www.cnj.jus. br/wp-content/uploads/conteudo/arquivo/2019/08/ justica_em_numeros20190919.pdf

25. Tribunal Regional Federal da $4^{\text {a }}$ Região, Seção Judiciária do Paraná. Resolução no 53, de 09 de junho de 2015. Regulamenta o teletrabalho no âmbito da Justiça Federal de $1^{\circ}$ e $2^{\circ}$ Graus da $4^{\mathrm{a}}$ Região e dá outras providências. Porto Alegre: TRF4; 2015.

26. Tribunal Regional Federal da $4^{\text {a }}$ Região. Resolução $\mathrm{n}^{\circ}$ 92, de 28 de maio de 2013. Regulamenta o teletrabalho no âmbito da Justiça Federal de $1^{\circ} \mathrm{e}$ $2^{\circ}$ Graus da $4^{\mathrm{a}}$ Região e dá outras providências. Porto Alegre: TRF4; 2013.

27. International Labour Organization. Teleworking during the COVID-19 pandemic and beyond: A Practical Guide. Geneva: ILO; 2020 [cited 2020 aug 16]. Available from: https://www.ilo.org/ wcmsp5/groups/public/---ed_protect/---protrav/--travail/documents/publication/wcms_751232.pdf

28. Alemão I, Barroso MRC. O teletrabalho e o repensar das categorias tempo e espaço. Enfoques. 2012;11(1):73-88.

29. Conselho Nacional de Justiça (BR). Resolução $\mathrm{n}^{\mathrm{o}} 298$, de 22 de outubro de 2019. Altera a Resolução n ${ }^{\circ}$ 227/2016, de 14 de junho de 2016 , que regulamenta o teletrabalho no âmbito do Poder 
Judiciário. Brasília, DF: CNJ; 2019 [citado em 30 abr. 2020] Disponível em: https://atos.cnj.jus.br/ atos/detalhar/3109

30. Portugal. Lei $n^{0} 7 / 2009$. Aprova a revisão do Código do Trabalho. Diário da República [Internet]. 12 fev. 2009 [citado em 29 abr. 2020]:30(1). Disponível em: https://data.dre.pt/eli/lei/7/2009/02/12/p/dre/pt/html

31. Tribunal Regional Federal da $3^{\text {a }}$ Região. Portaria Conjunta Pres/Core $\mathrm{n}^{\circ}$ 5, de 22 de abril de 2020. Dispõe sobre medidas complementares às Portarias Conjuntas PRES/CORE $\mathrm{n}^{\circ}$ 1, 2 e 3 de 2020 para enfrentamento da emergência de saúde pública de importância internacional decorrente do novo Coronavírus. São Paulo: TRF3; 2020.

32. Tribunal Regional Federal da $4^{\mathrm{a}}$ Região, Seção Judiciária do Paraná. Resolução no 18/2020. Dispõe sobre o regime de plantão extraordinário e outras medidas temporárias e emergenciais de prevenção ao contágio e à transmissão do novo coronavírus (COVID-19) no âmbito da Justiça Federal de Primeiro e Segundo Graus da $4^{\mathrm{a}}$ Região. Porto Alegre: TRF4; 2020.

33. Tribunal Regional Federal da $5^{\mathrm{a}}$ Região. Presidência Ato $n^{\circ} 112 / 2020$. Dispõe sobre novas medidas de prevenção relativas ao COVID-19. Recife: TRF5; 2020.

34. Tribunal Regional Federal da $2^{\mathrm{a}}$ Região. Resolução $\mathrm{n}^{\mathrm{O}}$ TRF2-RSP-2020/00012, de 26 de março de 2020. Dispõe sobre medidas temporárias de prevenção ao contágio pelo novo Coronavírus (COVID-19), considerando a classificação de pandemia pela Organização Mundial de Saúde (OMS), no âmbito da Justiça Federal da $2^{\text {a }}$ Região. Rio de Janeiro: TRF2; 2020.

35. Tribunal Regional Federal da $1^{\mathrm{a}}$ Região. Resolução Presi $n^{\circ}$ 9985909, de 20 de março de 2020. Dispõe, no âmbito da Justiça Federal da $1^{\text {a }}$ Região, sobre o regime de Plantão Extraordinário, e amplia medidas temporárias de prevenção e redução dos riscos de disseminação e contágio pelo Corononavírus Covid-19. Brasília, DF: TRF1; 2020.

36. Conselho Nacional de Justiça (BR). Resolução $\mathrm{n}^{\circ} 314$, de 20 de abril 2020. Prorroga, no âmbito do Poder Judiciário, em parte, o regime instituído pela Resolução n ${ }^{\circ} 313$, de 19 de março de 2020, modifica as regras de suspensão de prazos processuais e dá outras providências. Brasília, DF: CNJ; 2020.

37. Conselho Nacional de Justiça (BR).

Produtividade Semanal do Poder Judiciário. Regime de teletrabalho em razão do COVID-19 [Internet]. 2020 [cited 2020 apr 29]. Available from: https://paineisanalytics.cnj.jus.br/ single/?appid =ba21c495-77c8-48d4-85ecccd2f707b18c\&sheet =b45a3a06-9fe1-48dc-97ca52e929f89e69\&

38. Tribunal Regional Federal da $4^{\text {a }}$ Região, Seção Judiciária do Paraná. Resolução no 21/2020. Dispõe sobre medidas operacionais relativas ao teletrabalho integral compulsório nas unidades jurisdicionais e administrativas da Justiça Federal de Primeiro e Segundo Graus da $4^{\text {a }}$ Região. Porto Alegre: TRF4; 2020.

39. Brasil. Órgãos poderão ceder computadores para servidores em teletrabalho. Portal do Servidor [Internet]. 25 mar 2020 [citado em 29 abr. 2020]. Disponível em: https://www.anasps.org.br/ servidor-orgaos-poderao-ceder-computadores-parateletrabalho/

40. Supremo Tribunal Federal (BR). Resolução $n^{\circ}$ 677 , de 29 de abril de 2020. Estabelece medidas de médio prazo para gestão das atividades do Tribunal. Brasília, DF: STF; 2020.

41. Barros AM, Silva JRG da. Percepções dos indivíduos sobre as consequências do teletrabalho na configuração home-office: estudo de caso na Shell Brasil. Cad EBAPE BR. 2010;8(1):71-91.

42. Charalampous M, Grant CA, Tramontano C, Michailidis E. Systematically reviewing remote e-workers' well-being at work: a multidimensional approach. Eur J Work Organ Psychol. 2019;28(1):51-73.

43. Antunes R. Coronavírus: O trabalho sob fogo cruzado (Pandemia Capital). São Paulo: Boitempo Editorial; 2020. 